\title{
Inhibition of autophagy enhances apoptosis induced by bortezomib in AML cells
}

\author{
LEI JIANG, YI-MING ZHAO and MING-ZHEN YANG
}

Department of Haematology, The Fourth Affiliated Hospital of Anhui Medical University, Hefei, Anhui 230012, P.R. China

Received March 8, 2020; Accepted November 12, 2020

DOI: $10.3892 / \mathrm{ol} .2020 .12370$

\begin{abstract}
Bortezomib is a novel proteasome inhibitor, which has been successfully used to treat mantle cell lymphoma and multiple myeloma. However, the direct effects of bortezomib on acute promyelocytic leukaemia (APL) have not been fully investigated. In the present study, the WST-8 assay, western blotting, flow cytometry, monodansylcadaverine staining and transmission electron microscopy were performed. It was demonstrated that bortezomib treatment induced a timeand dose-dependent decrease in the viability of NB4 cells. Bortezomib treatment induced cell apoptosis in NB4 cells, as assessed by Annexin V/propidium iodide analysis, and the detection of cleaved caspase-3, cleaved poly(ADP-ribose) polymerase, Bax and Bcl-2 expression. Furthermore, bortezomib treatment induced autophagy in NB4 cells, as indicated by autophagosome formation, p62 degradation, LC3-I to LC3-II conversion and formation of acidic autophagic vacuoles. Notably, autophagy induced by bortezomib was initiated prior to apoptosis. Inhibition of autophagy by knocking down Beclin-1 expression increased bortezomib-induced apoptosis in NB4 cells. Therefore, the present study revealed that the combination of bortezomib and autophagy inhibition may be a potential treatment strategy for APL.
\end{abstract}

\section{Introduction}

Acute promyelocytic leukaemia (APL), a distinct subtype of acute myeloid leukaemia (AML), responds well to differentiation therapy (1). All-trans retinoic acid (ATRA) has been used successfully to treat APL as a differentiation therapy (1). Therapeutic concentrations of ATRA induce a conformational change in the promyelocytic leukemia-retinoic acid $\alpha$ receptor $(\mathrm{RAR} \alpha)$ molecular complex, the leukaemia-generating fusion protein which leads to the development of APL (2). When

Correspondence to: Professor Ming-Zhen Yang, Department of Haematology, The Fourth Affiliated Hospital of Anhui Medical University, 100 Huai Hai Road, Hefei, Anhui 230012, P.R. China E-mail: yangmz89@163.com

Key words: bortezomib, autophagy, apoptosis, NB4 cells, acute promyelocytic leukaemia the corepressors are released from the complex, normal RAR $\alpha$-responsive gene regulation occurs, which induces terminal APL cell differentiation $(2,3)$. However, previous studies have demonstrated that ring finger protein 8 is responsible for ATRA resistance in variant APL with general transcription factor IIi/RAR $\alpha$ fusion, and inhibition of the ubiquitin-proteasome signalling pathway contributes to the reversion of ATRA resistance (4). A previous study demonstrated that RAR $\alpha$ and its fusion proteins are degraded by the ubiquitin/proteasome signalling pathway, which may limit ATRA-mediated myeloid cell differentiation (5). A small proportion of patients do not respond to induction therapy, which makes variant APL a challenging disease to treat (1).

Bortezomib, a synthetic, biologically active boronic acid dipeptide, is commercially available, and is the first proteasome inhibitor approved by the US Food and Drug Administration (6). This novel agent has been approved for the treatment of multiple myeloma (MM) (7) and mantel cell lymphoma (8), as well as other types of haematological malignancies (6), even in relapsed or refractory patients (9). Furthermore, it exhibits antitumor properties in certain types of solid tumour cells and in murine xenograft models $(10,11)$. The anticancer activity of this drug is exerted via several different mechanisms, including cell proliferation inhibition, apoptosis and autophagy induction, as well as anti-angiogenesis (12). Therefore, bortezomib may serve as a potent therapeutic to overcome resistance to conventional chemotherapy.

Autophagy is an orchestrated process in which damaged organelles and misfolded proteins are engulfed by autophagosomes, which then fuse with lysosomes for degradation (13). Generally, autophagy is critical for maintaining cellular homeostasis during stress and adverse conditions (14). A previous study suggested that autophagy may represent a potential therapeutic target for cancer treatment (15). Bortezomib-induced autophagy has been demonstrated in certain types of cancer cells, such as non-small cell lung cancer cells, glioblastoma cells and B-cell acute lymphoblastic leukaemia cells (16-18). It has been previously reported that bortezomib, combined with arsenic trioxide, exhibits a beneficial effect in APL therapy (19). However, the exact molecular mechanisms by which bortezomib exerts its effects on APL cells remain unknown.

In the present study, bortezomib treatment reduced the viability of NB4 cells in a time- and dose-dependent manner, and the effects of bortezomib treatment on apoptosis and 
autophagy were investigated in NB4 cells. Furthermore, inhibition of autophagy increased cell apoptosis induced by bortezomib in NB4 cells, highlighting a potential novel treatment strategy for APL in addition to differentiation therapy.

\section{Materials and methods}

Reagents. Antibodies against Bax (cat. no. 2774), Bcl-2 (cat.no. 15071), Beclin-1 (cat. no.3738), caspase-3 (cat.no.9662), poly(ADP-ribose) polymerase (PARP; cat. no. 9532) and sequestosome 1/p62 (cat. no. 88588) were purchased from Cell Signaling Technology, Inc.. Antibodies against $\beta$-actin (cat. no. 60008-1) were purchased from ProteinTech Group, Inc. Antibodies against LC3B (cat. no. L7543) were purchased from Sigma-Aldrich; Merck KGaA. Bortezomib (cat. no. DELS800) was purchased from BSP Pharmaceuticals S.p.A., dissolved in $0.9 \%$ normal saline solution and aliquoted at a stock concentration of $2 \mathrm{mM}$, and stored at $-20^{\circ} \mathrm{C}$.

Cell culture. The human APL NB4 and HL-60 cell lines were obtained from The Cell Bank of Type Culture Collection of The Chinese Academy of Sciences. NB4 and HL-60 cells were cultured in RPMI-1640 medium (Gibco; Thermo Fisher Scientific, Inc.) supplemented with $10 \%$ heat-inactivated FBS (HyClone; Cytiva) and $50 \mu \mathrm{g} / \mathrm{ml}$ penicillin and $50 \mu \mathrm{g} / \mathrm{ml}$ streptomycin (Beijing Solarbio Science \& Technology Co., Ltd.) in a humidified incubator at $37^{\circ} \mathrm{C}$ with $5 \% \mathrm{CO}_{2}$.

Water-soluble tetrazolium salts (WST)- 8 assay. The cytotoxicity of bortezomib in NB4 cells was determined using a WST-8 assay. Briefly, exponentially growing NB4 cells $\left(5 \times 10^{3}\right.$ cells/well) were cultured in 96-well plates for $24 \mathrm{~h}$ and then treated with various concentrations of bortezomib $(0,1.25$, $2.5,5,10,20$ and $40 \mathrm{nM}$ ) for $24-48 \mathrm{~h}$ at $37^{\circ} \mathrm{C}$. Subsequently, cell viability was evaluated by incubating with WST-8 (Dojindo Molecular Technologies, Inc.) for $1 \mathrm{~h}$ at $37^{\circ} \mathrm{C}$ according to the manufacturer's protocol in triplicate. The absorbance of samples was measured at $450 \mathrm{~nm}$ using an EnSpire Multilabel Plate Reader (PerkinElmer, Inc.).

Flow cytometry analysis of cell apoptosis. The apoptotic effect of bortezomib was detected using an Annexin V-FITC/propidium iodide (PI) Apoptosis Detection kit (cat. no. KGA107; Nanjing KeyGen Biotech Co., Ltd.). Briefly, cells $\left(2 \times 10^{5}\right.$ cells/well) were cultured in 6-well plates and treated with various concentrations of bortezomib for $24-48 \mathrm{~h}$ at $37^{\circ} \mathrm{C}$. Subsequently, cells were washed twice in PBS and then stained with Annexin V-FITC and PI for 15 min at room temperature. Cell apoptosis was detected using a flow cytometer (FACSCalibur; BD Biosciences) and analysed using CellQuest analysis version 5.0 software (BD Biosciences).

Monodansylcadaverine (MDC) staining. The autophagic vacuoles in NB4 and HL-60 cells were visualized using MDC staining. Briefly, cells ( $2 \times 10^{5}$ cells/well) were cultured in 6-well plates and treated with bortezomib $(20 \mathrm{nM})$ for $24 \mathrm{~h}$ at $37^{\circ} \mathrm{C}$. Subsequently, the incubated cells were treated with MDC (cat. no. 30432; Sigma-Aldrich; Merck KGaA) at a concentration of $0.05 \mathrm{mM}$ in PBS at $37^{\circ} \mathrm{C}$ for $1 \mathrm{~h}$. Subsequently, the cells were centrifuged onto coverslips in $1,500 \mathrm{xg}$ for $15 \mathrm{~min}$ at room temperature, in which the coverslips were pre-coated with poly-L-lysine (cat. no. P8920; Sigma-Aldrich; Merck KGaA) at $4^{\circ} \mathrm{C}$ for $1 \mathrm{~h}$. The cells were fixed with $4 \%$ paraformaldehyde (cat. no. 158127; Sigma-Aldrich; Merck KGaA) at $4^{\circ} \mathrm{C}$ for $10 \mathrm{~min}$ and then the coverslips containing the fixed cells were washed twice with PBS. The MDC-stained cells were analysed using a fluorescence microscope at a magnification of 10x40 (eye lens x objective lens; excitation, $380 \mathrm{~nm}$; emission, $525 \mathrm{~nm}$; DP73; Olympus Corporation).

Lentiviral transfection. Lentiviral particles containing short hairpin RNA (shRNA/sh) Beclin-1 (cat. no. 131209BZ; 5'-CCGACTTGTTCCTTACGGAAA-3') and shRNA negative control (shCTRL; cat. no. 131127CZ; 5'-TTCTCCGAA CGTGTCACGTTTC-3') expression vectors were obtained from Shanghai GenePharma Co., Ltd., and were then cloned into pGLV3/H1/GFP-Puro vector (Shanghai GenePharma Co., Ltd.). High titre production of lentivector was achieved by transiently co-transfecting $293 \mathrm{~T}$ cells (The Cell Bank of Type Culture Collection of The Chinese Academy of Sciences) with lentiviral packaging plasmids, $3 \mu \mathrm{g}$ pGag/Pol, $1 \mu \mathrm{g} \mathrm{pRev}$, $1 \mu \mathrm{g}$ pVSV-G (Shanghai GenePharma Co., Ltd.) and $3 \mu \mathrm{g}$ shBeclin-1 expressing constructs via Lipofectamine ${ }^{\circledR} 2000$ (cat. no. 11668-500; Invitrogen; Thermo Fisher Scientific, Inc.) at $37^{\circ} \mathrm{C}$ for $6 \mathrm{~h}$, followed by a further 72 -h culture period with replaced medium. The lentivirus particles were collected by centrifuging the cell supernatant at $1,500 \mathrm{x} \mathrm{g}$ for $4 \mathrm{~min}$ at $4^{\circ} \mathrm{C}$. Subsequently, the supernatant in the centrifuge tube was filtered using a $0.45-\mu \mathrm{m}$ filter and centrifuged at $40,000 \mathrm{x} \mathrm{g}$ for $2 \mathrm{~h}$ at $4^{\circ} \mathrm{C}$. Exponentially growing NB4 or HL-60 cells were seeded and cultured in 6-well plates, and exposed to the lentivirus particles (shBeclin-1 or shCTRL) at $37^{\circ} \mathrm{C}$ for $2 \mathrm{~h}$ at a multiplicity of infection of $1 \times 10^{8} \mathrm{TU} / \mathrm{ml}$, followed by a further 48-h culture period before subsequent experiments. Subsequently, cells stably expressing shBeclin- 1 and shCTRL vectors were selected using puromycin as a selection pressure $(2 \mu \mathrm{g} / \mathrm{ml})$.

Detection of autophagosomes by transmission electron microscopy. NB4 or HL-60 cells $\left(2 \times 10^{5}\right.$ cells/well) were cultured in 6-well plates and treated with bortezomib $(20 \mathrm{nM})$ for $24 \mathrm{~h}$ at $37^{\circ} \mathrm{C}$. The collected cells were then fixed with $2.5 \%$ glutaraldehyde for $2 \mathrm{~h}$ at $4^{\circ} \mathrm{C}$, washed with PBS three times and fixed with $1 \%$ osmium tetroxide for $1 \mathrm{~h}$ at $4^{\circ} \mathrm{C}$. Following gradient dehydration with ethanol-acetone, the cells were embedded in epoxy for $4-6 \mathrm{~h}$ at $4^{\circ} \mathrm{C}$ for sectioning. The thin sections (50-70-nm-thick) were doubly stained with $1 \%(w / v)$ uranyl acetate for $30 \mathrm{~min}$ at room temperature and lead citrate for $20 \mathrm{~min}$ at room temperature, and then observed using a JEM 1011CX transmission electron microscope (JEOL, Ltd.).

Western blotting. The treated NB4 or HL-60 cells were washed with cold PBS twice and then lysed in RIPA lysis buffer [Tris $(50 \mathrm{mM}) \mathrm{pH} 8.0$, sodium chloride $(150 \mathrm{mM}), 0.5 \%$ sodium deoxycholate, $0.1 \%$ SDS and $1 \%$ NP-40] supplemented with protease inhibitors $\left[\mathrm{Na}_{3} \mathrm{VO}_{4}(1 \mathrm{mM})\right.$, leupeptin $(1 \mu \mathrm{g} / \mathrm{ml})$ and PMSF $(1 \mathrm{mM})]$ on ice for $30 \mathrm{~min}$. Protein concentration was determined using a BCA assay and protein samples (20 $\mu \mathrm{g} / \mathrm{lane})$ were separated by SDS-PAGE $(8-12 \%)$ and then 


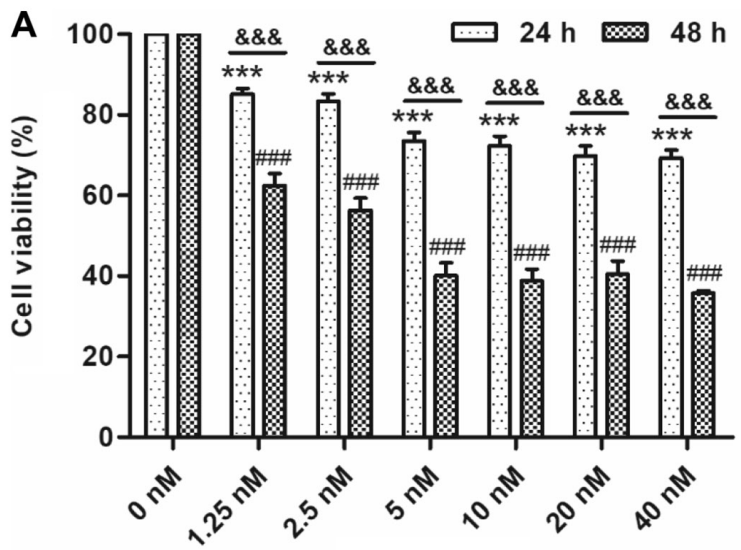

C

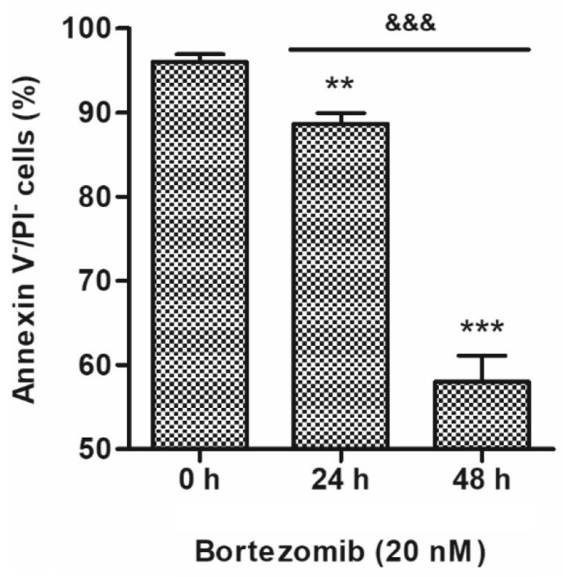

B

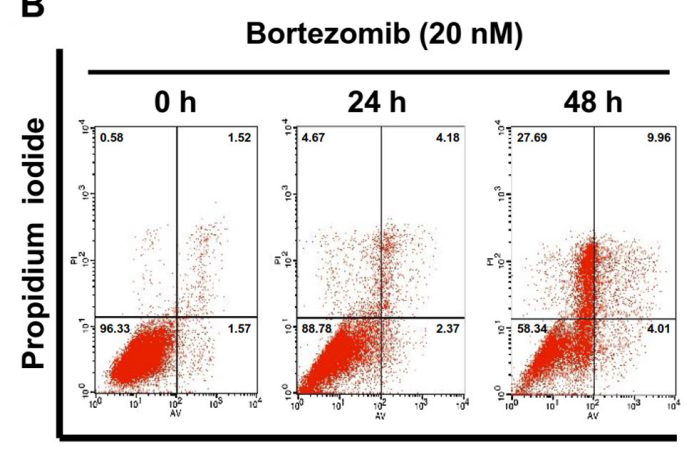

Annexin V-FITC

D

Bortezomib (20 nM)

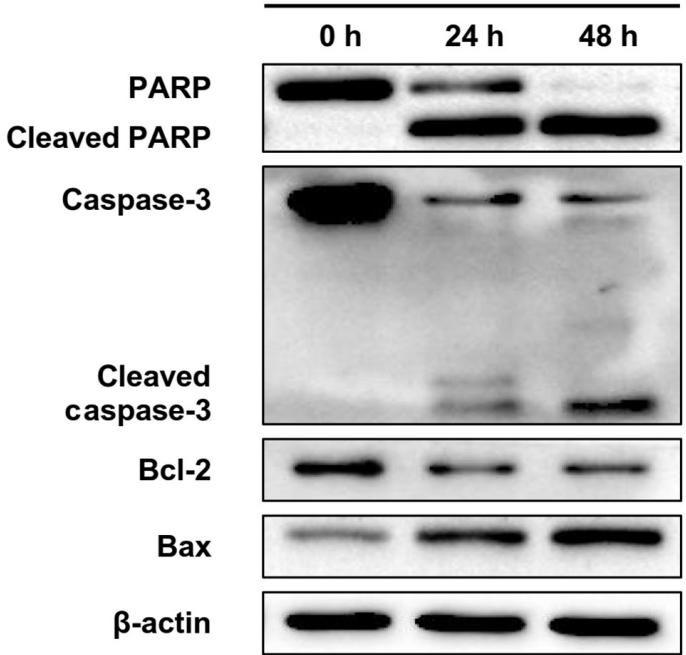

Figure 1. Bortezomib reduces cell viability and induces cell apoptosis in NB4 cells. (A) Cells were treated with bortezomib ( $0,1.25,2.5,5,10,20$ and 40 nM) for 24 or $48 \mathrm{~h}$, and cell viability was assessed using a water-soluble tetrazolium salts- 8 assay. Error bars represent the standard error of the mean of three independent repeats. ${ }^{* * *} \mathrm{P}<0.001$ vs. $0 \mathrm{nM} 24 \mathrm{~h} .{ }^{\# \# \#} \mathrm{P}<0.001$ vs. $0 \mathrm{nM} 48$ h. ${ }^{\& \& \&} \mathrm{P}<0.00124$ vs. 48 h. (B) Cells were treated with bortezomib (20 nM) for 0,24 and $48 \mathrm{~h}$, and then cells were stained with Annexin V and PI. The percentage of apoptotic cells was assessed using FACS analysis. (C) Bar graph showing the percentage of cells negative for Annexin V and PI staining. Data are presented as the mean \pm standard deviation of three independent repeats. ${ }^{* *} \mathrm{P}<0.01$ and ${ }^{* * *} \mathrm{P}<0.001$ vs. control ( 0 h). \&\&\& $\mathrm{P}<0.00124$ vs. 48 h. (D) Cells were treated with bortezomib (20 nM) for 0,24 and 48 h, and the expression levels of cleaved PARP, cleaved caspase-3, Bcl-2 and Bax were assessed by western blotting. PARP, poly(ADP-ribose) polymerase; PI, propidium iodide.

transferred onto a nitrocellulose membrane (EMD Millipore). Subsequently, membranes were blocked using $5 \%(\mathrm{w} / \mathrm{v})$ skimmed milk at room temperature for $1 \mathrm{~h}$, and then washed with TBS with $0.1 \%$ Tween-20 three times. Subsequently, the membranes were incubated with primary antibodies $(1: 1,000)$ for $12 \mathrm{~h}$ at $4^{\circ} \mathrm{C}$. Following incubation with anti-mouse (1:5,000; cat. no. ab97040; Abcam) or anti-rabbit (1:5,000; cat. no. ab7090; Abcam) HRP-conjugated secondary antibodies at room temperature for $1 \mathrm{~h}$, signals were visualized using an enhanced chemiluminescence western blotting kit (cat. no. K-12045-D50; Advansta, Inc.) and analysed using Image Lab version 4.0 (Bio-Rad Laboratories, Inc.).

Statistical analysis. Data are presented as the mean \pm standard deviation of three independent experiments. GraphPad Prism 5 (GraphPad Software, Inc.) was used for statistical analysis, and unpaired Student's t-test (comparison of two groups) or one-way ANOVA followed by Sidak's multiple comparisons post hoc test (comparison of more than two groups) was used to determine the significance of differences among groups.
$\mathrm{P}<0.05$ was considered to indicate a statistically significant difference.

\section{Results}

Bortezomib reduces cell viability and induces cell apoptosis in NB4 cells. To determine the effects of bortezomib on cell viability, NB4 cells were treated with a range of concentrations of bortezomib for 24 and $48 \mathrm{~h}$. The WST- 8 assay revealed that bortezomib treatment resulted in a time- and dose-dependent inhibition of cell viability in NB4 cells (Fig. 1A). Reduction of cell viability reached a plateau with $20 \mathrm{nM}$ bortezomib treatment and this concentration was selected for all subsequent experiments. The apoptotic effect of bortezomib was determined by flow cytometry, the most convenient technique to study apoptotic cell death, and western blotting, a widely used technique for qualitative or semi-quantitative analysis of apoptosis (20). NB4 and HL-60 cells were treated with $20 \mathrm{nM}$ bortezomib for 0,24 and $48 \mathrm{~h}$, and apoptosis was determined using Annexin V/PI staining. The results 
A

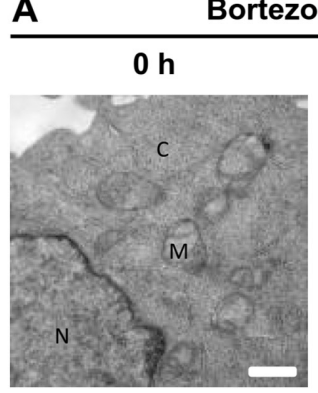

C

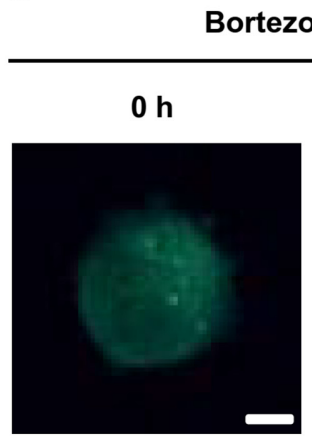

B
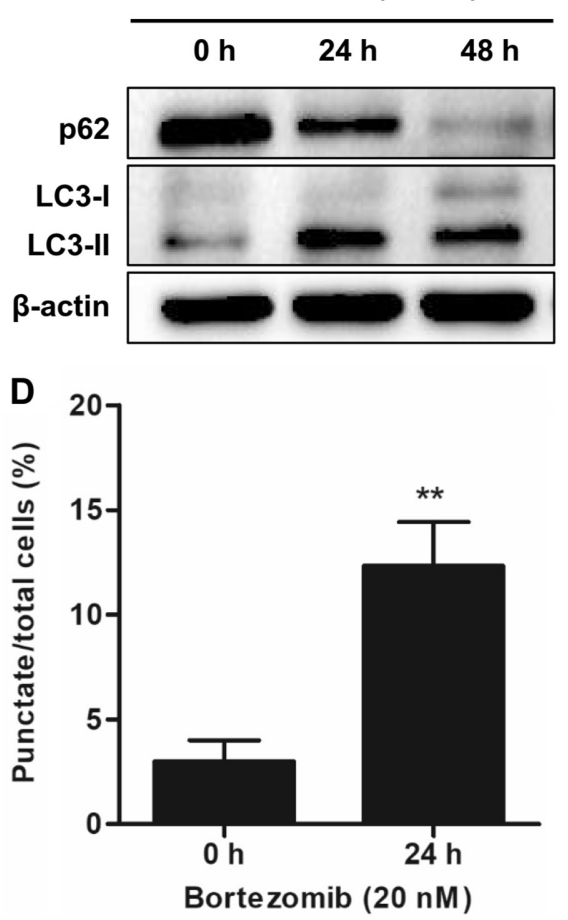

Figure 2. Bortezomib induces autophagy in NB4 cells. (A) Cells were treated with bortezomib (20 nM) for 0 or 24 h. Transmission electron microscopy was performed to detect autophagosomes. Arrows indicate the autophagosomes. Scale bar, $500 \mathrm{~nm}$. (B) Cells were treated with bortezomib (20 nM) for 0,24 and $48 \mathrm{~h}$. The expression levels of p62 and LC3 were assessed by western blotting. (C) Treated cells were stained with MDC, and staining was assessed using fluorescence microscopy to identify autophagic vacuoles. Scale bar, $50 \mu \mathrm{m}$. (D) Percentages of punctate dots were quantified by counting the number of cells exhibiting the punctate pattern of MDC staining among 100 cells. Data are presented as the mean \pm standard deviation of three independent repeats. ${ }^{* *} \mathrm{P}<0.01$ vs. control (0 h). M, mitochondrial structures; N, nucleus; C, cytoplasm; MDC, monodansylcadaverine.

indicated that bortezomib treatment significantly decreased live cells compared with the control cells ( 0 h; Figs. $1 \mathrm{~B}$ and $\mathrm{C}$ and S1A and B), indicating that apoptosis was increased. Bortezomib-induced apoptosis was further demonstrated by increased levels of cleaved caspase-3, cleaved PARP and Bax, and decreased expression levels of Bcl-2 (Figs. 1D and S1C).

Bortezomib induces autophagy in NB4 cells. To determine whether bortezomib could induce autophagy in NB4 and HL-60 cells, transmission electron microscopy was used to detect autophagosome formation following treatment with bortezomib. The presence of autophagosomes was increased in the bortezomib-treated cells compared with the control cells ( 0 h; Figs. 2A and S2A). Bortezomib treatment increased the expression levels of the autophagy-related protein LC3-II and decreased the levels of the autophagic marker p62 in a time-dependent manner (Figs. 2B and S2B). The presence of MDC staining was used as a marker of autophagic vacuoles (21). Bortezomib significantly increased the accumulation of MDC in treated cells compared with the control cells $(0 \mathrm{~h}$; Figs. 2C and D and S2C and D). These results demonstrated that bortezomib treatment induced autophagy in NB4 and HL-60 cells.

Autophagy occurs before apoptosis following treatment with bortezomib. The aforementioned results demonstrated that bortezomib induced apoptosis and autophagy in NB4 cells. A time-course study was performed to determine when apoptosis and autophagy were initiated following treatment

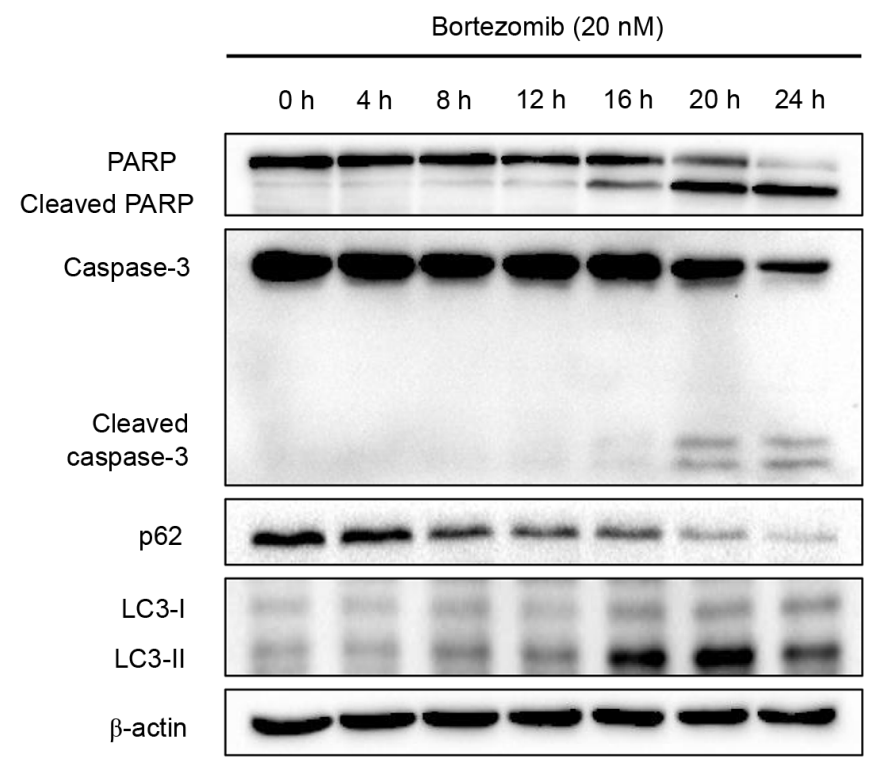

Figure 3. Bortezomib-induced autophagy is initiated before apoptosis Cells were treated with bortezomib $(20 \mathrm{nM})$ for the indicated time periods $(0,4,8,12,16,20$ and $24 \mathrm{~h})$ and the expression levels of cleaved caspase-3, cleaved PARP and p62, and LC3-I to LC3-II conversion were determined by western blotting. PARP, poly(ADP-ribose) polymerase.

with bortezomib. Apoptosis, as determined by PARP and caspase-3 cleavage levels, was detected at $16 \mathrm{~h}$ (cleaved PARP) or $20 \mathrm{~h}$ (cleaved caspase-3) after bortezomib treatment, whereas autophagy, as indicated by p62 degradation and LC3 
A
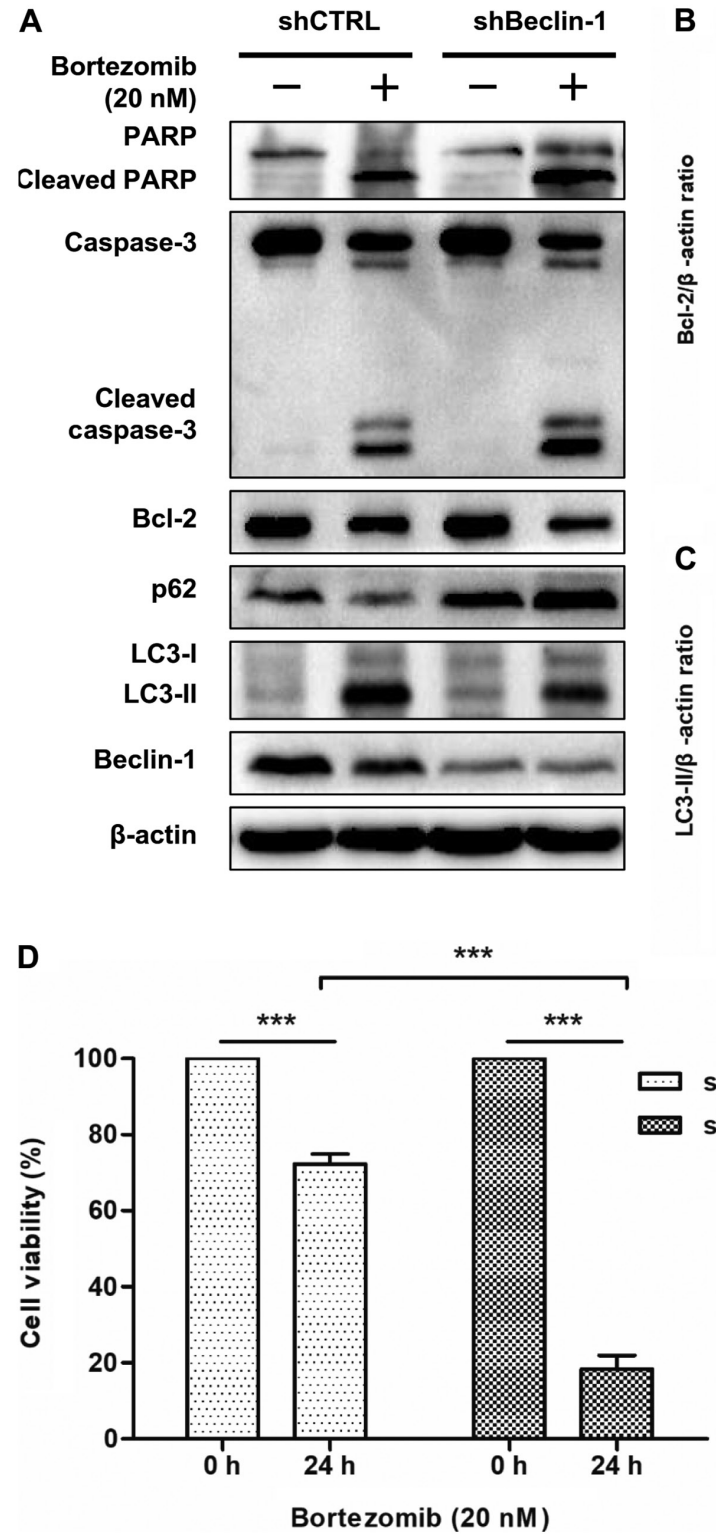

B
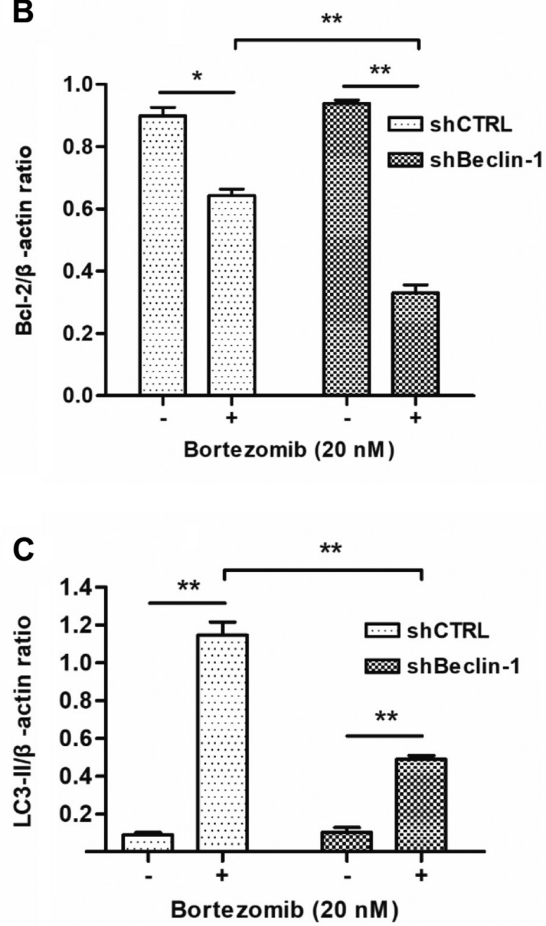

Figure 4. Downregulation of Beclin-1 enhances apoptosis and reduces cell viability induced by bortezomib in NB4 cells. Cells were infected with lentiviruses expressing shRNAs (non-targeting control or Beclin-1). Puromycin-resistant cells were pooled after each infection. (A) Cells transfected with the control shRNA and shBeclin-1 were treated with or without bortezomib (20 nM) for $24 \mathrm{~h}$, and the expression levels of cleaved caspase-3, cleaved PARP, Bcl-2, p62 and Beclin-1, and LC3-I to LC3-II conversion were determined by western blotting. (B) Ratio of Bcl-2 and $\beta$-actin expression levels. Data are presented as the mean \pm standard deviation of three independent repeats. ${ }^{*} \mathrm{P}<0.05$ and ${ }^{* *} \mathrm{P}<0.01$. (C) Ratio of LC3-II and $\beta$-actin expression levels. Data are presented as the mean \pm standard deviation of three independent repeats. ${ }^{* *} \mathrm{P}<0.01$. (D) Cells transfected with the control shRNA and shBeclin-1 were treated with bortezomib $(20 \mathrm{nM})$ for 0 and $24 \mathrm{~h}$, and cell viability was assessed using a water-soluble tetrazolium salts- 8 assay. Data are presented as the mean \pm standard deviation of three independent repeats. ${ }^{* * *} \mathrm{P}<0.001$. shRNA/sh, short hairpin RNA; CTRL, control; PARP, poly(ADP-ribose) polymerase.

conversion, was detected at an earlier time point (8 h; Fig. 3). Overall, these results indicated that bortezomib induced autophagy prior to apoptosis in NB4 cells.

Inhibition of autophagy using shRNA enhances cell apoptosis and reduces cell viability induced by bortezomib in NB4 cells. The role of autophagy in bortezomib-mediated apoptosis was further investigated by knocking down Beclin-1 expression using shRNA. As shown in Fig. 4A, the expression levels of Beclin-1 were markedly suppressed in NB4 cells transfected with the shRNA-Beclin-1 lentivirus, but not in those transfected with the non-targeting shRNA. Subsequently, shBeclin-1 was used to inhibit autophagy in order to determine the role of autophagy in apoptosis induced by bortezomib. Western blot analysis demonstrated that bortezomib treatment significantly decreased the expression levels of Bcl-2 (Fig. 4A and B) and LC3-II (Fig. 4A and C), and increased the expression levels of p62, cleaved PARP and cleaved caspase-3 (Fig. 4A) in shBeclin-1 NB4 cells compared with in shCTRL cells. The WST- 8 assay revealed that bortezomib treatment significantly decreased cell viability in shBeclin-1 NB4 cells compared with in shCTRL cells (Fig. 4D). These results indicated that inhibition of autophagy enhanced apoptosis in NB4 cells and HL-60 cells (Figs. 4A-C and S3) and decreased cell viability induced by bortezomib in NB4 cells (Fig. 4D). 


\section{Discussion}

Autophagy is an evolutionarily conserved process in which intracellular membrane structures sequester misfolded proteins and damaged organelles into autophagosomes for degradation, after which the contents are recycled (22). Generally, autophagy functions to maintain cellular homeostasis in response to stress and starvation (23). Increasing evidence has demonstrated that autophagy may protect cancer cells from anticancer drug treatments, and that suppression of autophagy enhances cancer cell death $(22,24)$. Our previous study demonstrated that, in haematological malignant cells, inhibition of autophagy by chloroquine, 3-methyladenine or a combination of these two agents enhanced the apoptosis induced by chemotherapy (15). In the present study, it was demonstrated that bortezomib treatment inhibited cell viability, and induced autophagy and apoptosis in NB4 cells. Additionally, it was demonstrated that inhibition of autophagy enhanced apoptosis induced by bortezomib in NB4 cells.

After revealing that bortezomib induced apoptosis and autophagy in NB4 cells, the sequence of these two events was determined. Therefore, a time-dependent study was performed and the results revealed that autophagy occurred before apoptosis, as demonstrated by the upregulation of apoptosis and autophagy markers. p62 degradation and LC-I/LC-II conversion occurred after $8 \mathrm{~h}$, whereas cleaved caspase- 3 and cleaved PARP were detected after $16 \mathrm{~h}$. Subsequently, to further clarify the role of autophagy in bortezomib-induced cell death, shBeclin-1 was used to knockdown Beclin-1 expression, and the role of autophagy was evaluated more directly. Notably, bortezomib alone had an apoptosis- and autophagy-inducing effect; however, following knockdown using shBeclin-1, autophagy was blocked, as demonstrated by the increased p62 expression and decreased conversion of LC-II. Bortezomib treatment in the knockdown cells increased the levels of cleaved caspase- 3 and cleaved PARP, and decreased the expression levels of Bcl-2, indicating that autophagy inhibition in combination with proteasome suppression resulted in increased apoptosis. Therefore, it was hypothesized that when tumour cells encounter chemotherapeutic drugs or stress, autophagy occurs first to protect the tumour cells from harm. If stress persists, the cells will then undergo apoptosis, indicating that autophagy may serve a role in protecting tumour cells. A previous study has demonstrated that autophagy serves a protective role in apoptotic cell death under conditions of stress and starvation, as well as contributing to drug resistance (25). It has been reported that inhibition of autophagy augments 5-fluorouracil chemotherapy in colon cancer cells (26) and overcomes glucocorticoid resistance in lymphoid malignant cells (15). Conversely, studies have also demonstrated that autophagy contributes to tumour cell death $(27,28)$. A possible explanation for the contradictory results stemming from the same process may lie in the stimulus type, organism development, nutrient availability and the signalling pathways involved (29). Previous studies have demonstrated that the PI3K-AKT-mTOR signalling pathway, which is activated in several types of cancer, is involved in autophagy regulation (21,30). 3-Methyladenine inhibits class III PI3K, thus blocking autophagic sequestration at the initial stage, which has been widely used in several studies $(21,30)$. Therefore, further investigations are required to clarify the signalling pathway involved in bortezomib-treated APL.

Bortezomib is a proteasome inhibitor that has been used to treat $\mathrm{MM}$ and mantel cell lymphoma for decades $(8,9)$. In $\mathrm{AML}$, constitutive activity of $\mathrm{NF}-\kappa \mathrm{B}$ has been detected in $40 \%$ of cases and its aberrant activity enables leukaemia cells to evade apoptosis and stimulate proliferation $(31,32)$. Bortezomib, which is also an NF- $\kappa \mathrm{B}$ inhibitor, is widely used in the treatment of AML as a therapeutic strategy in combination with other chemotherapeutic agents $(33,34)$. Other possible mechanisms involved in bortezomib-treated AML cells are as follows: i) Riccioni et al (35) demonstrated that bortezomib mediates apoptosis by activating caspase- 8 and caspase- 3 in M4 and M5 cells; ii) Yan et al (19) reported that protein kinase $C \delta$ serves an important role in bortezomib- and arsenic trioxide-induced apoptosis, and that the combined regimen may serve as a potential therapeutic remedy for the treatment of leukaemia; and iii) Ying et al (36) revealed that bortezomib sensitizes AML cells to ATRA-induced differentiation by modifying the RAR $\alpha /$ STAT1 axis. Therefore, further studies focusing on the mechanisms of combination of bortezomib and autophagy inhibition may provide novel insights into APL treatment. Given the hypothesis of autophagy inhibition as an anticancer strategy, more data in in vivo models should be accumulated in future studies.

In conclusion, the present study demonstrated that bortezomib inhibited cell viability and induced autophagy, which occurred prior to apoptosis. Furthermore, it was demonstrated that inhibition of autophagy using shBeclin-1 enhanced the anticancer effects of bortezomib. The present study improved the understanding of the combined effects of bortezomib on autophagy inhibition in haematological malignancy chemotherapy.

\section{Acknowledgements}

Not applicable.

\section{Funding}

The present study was supported by the Natural Science Foundation of Anhui Higher Education Institutions (grant no. KJ2017A833; to LJ) and the Backbone of Scientific Research (to LJ).

\section{Availability of data and materials}

All data generated or analyzed during this study are included in this published article.

\section{Authors' contributions}

LJ and MZY designed the study. LJ performed all experiments. YMZ analyzed the results. LJ wrote, reviewed and edited the manuscript. All authors read and approved the final manuscript.

\section{Ethics approval and consent to participate}

Not applicable. 


\section{Patient consent for publication}

Not applicable.

\section{Competing interests}

The authors declare that they have no competing interests.

\section{References}

1. Raffoux E, Rousselot P, Poupon J, Daniel MT, Cassinat B Delarue R, Taksin AL, Réa D, Buzyn A, Tibi A, et al: Combined treatment with arsenic trioxide and all-trans-retinoic acid in patients with relapsed acute promyelocytic leukemia. J Clin Oncol 21: 2326-2334, 2003.

2. Nitto T and Sawaki K: Molecular mechanisms of the antileukemia activities of retinoid and arsenic. J Pharmacol Sci 126: 179-185, 2014

3. Jing Y and Waxman S: The design of selective and non-selective combination therapy for acute promyelocytic leukemia. Curr Top Microbiol Immunol 313: 245-269, 2007.

4. Yan W, Li J, Zhang Y, Yin Y, Cheng Z, Wang J, Hu G, Liu S, Wang Y, Xu Y, et al: RNF8 is responsible for ATRA resistance in variant acute promyelocytic leukemia with GTF2I/RARA fusion, and inhibition of the ubiquitin-proteasome pathway contributes to the reversion of ATRA resistance. Cancer Cell Int 19: 84, 2019.

5. Kopf E, Plassat JL, Vivat V, de The H, Chambon P and Rochette-Egly C: Dimerization with retinoid X receptors and phosphorylation modulate the retinoic acid-induced degradation of retinoic acid receptors alpha and gamma through the ubiquitin-proteasome pathway. J Biol Chem 275: 33280-33288, 2000.

6. Robak P and Robak T: Bortezomib for the treatment of hematologic malignancies: 15 Years later. Drugs R D 19: 73-92, 2019.

7. Scott K, Hayden PJ, Will A, Wheatley K and Coyne I: Bortezomib for the treatment of multiple myeloma. Cochrane Database Syst Rev 4: CD010816, 2016.

8. Yazbeck V, Shafer D, Perkins EB, Coppola D, Sokol L, Richards KL, Shea T, Ruan J, Parekh S, Strair R, et al: A phase II trial of bortezomib and vorinostat in mantle cell lymphoma and diffuse large B-cell lymphoma. Clin Lymphoma Myeloma Leuk 18: 569-575.e1, 2018.

9. Richardson PG, Oriol A, Beksac M, Liberati AM, Galli M, Schjesvold F, Lindsay J, Weisel K, White D, Facon T, et al Pomalidomide, bortezomib, and dexamethasone for patients with relapsed or refractory multiple myeloma previously treated with lenalidomide (OPTIMISMM): A randomised, open-label, phase 3 trial. Lancet Oncol 20: 781-794, 2019.

10. Caravita T, de Fabritiis P, Palumbo A, Amadori S and Boccadoro M: Bortezomib: Efficacy comparisons in solid tumors and hematologic malignancies. Nat Clin Pract Oncol 3 374-387, 2006.

11. Nencioni A, Grunebach F, Patrone F, Ballestrero A and Brossart P: Proteasome inhibitors: Antitumor effects and beyond. Leukemia 21: 30-36, 2007.

12. Roccaro AM, Vacca A and Ribatti D: Bortezomib in the treatment of cancer. Recent Pat Anticancer Drug Discov 1: 397-403, 2006.

13. Kondo Y, Kanzawa T, Sawaya R and Kondo S: The role of autophagy in cancer development and response to therapy. Nat Rev Cancer 5: 726-734, 2005.

14. Mathew R, Karantza-Wadsworth V and White E: Role of autophagy in cancer. Nat Rev Cancer 7: 961-967, 2007.

15. Jiang L, Xu L, Xie J, Li S, Guan Y, Zhang Y, Hou Z, Guo T, Shu X, Wang C, et al: Inhibition of autophagy overcomes glucocorticoid resistance in lymphoid malignant cells. Cancer Biol Ther 16: 466-476, 2015.

16. Wu G, Li H, Ji Z, Jiang X, Lei Y and Sun M: Inhibition of autophagy by autophagic inhibitors enhances apoptosis induced by bortezomib in non-small cell lung cancer cells. Biotechnol Lett 36: 1171-1178, 2014.

17. Zhang X, Li W, Wang C, Leng X, Lian S, Feng J, Li J and Wang H: Inhibition of autophagy enhances apoptosis induced by proteasome inhibitor bortezomib in human glioblastoma U87 and U251 cells. Mol Cell Biochem 385: 265-275, 2014.
18. Wang Z, Zhu S, Zhang G and Liu S: Inhibition of autophagy enhances the anticancer activity of bortezomib in B-cell acute lymphoblastic leukemia cells. Am J Cancer Res 5: 639-650, 2015.

19. Yan H, Wang YC, Li D, Wang Y, Liu W, Wu YL and Chen GQ: Arsenic trioxide and proteasome inhibitor bortezomib synergistically induce apoptosis in leukemic cells: The role of protein kinase Cdelta. Leukemia 21: 1488-1495, 2007.

20. Galluzzi L, Aaronson SA, Abrams J, Alnemri ES, Andrews DW, Baehrecke EH, Bazan NG, Blagosklonny MV, Blomgren K, Borner C, et al: Guidelines for the use and interpretation of assays for monitoring cell death in higher eukaryotes. Cell Death Differ 16: 1093-1107, 2009.

21. Klionsky DJ, Abdelmohsen K, Abe A, Abedin MJ, Abeliovich H, Acevedo Arozena A, Adachi H, Adams CM, Adams PD, Adeli $\mathrm{K}$, et al: Guidelines for the use and interpretation of assays for monitoring autophagy (3rd edition). Autophagy 12: 1-222, 2016.

22. Folkerts H, Hilgendorf S, Vellenga E, Bremer E and Wiersma VR: The multifaceted role of autophagy in cancer and the microenvironment. Med Res Rev 39: 517-560, 2019.

23. White E: The role for autophagy in cancer. J Clin Invest 125: 42-46, 2015.

24. Levy JMM, Towers CG and Thorburn A: Targeting autophagy in cancer. Nat Rev Cancer 17: 528-542, 2017.

25. Li YJ, Lei YH, Yao N, Wang CR, Hu N, Ye WC, Zhang DM and Chen ZS: Autophagy and multidrug resistance in cancer. Chin J Cancer 36: 52, 2017.

26. Li J, Hou N, Faried A, Tsutsumi S and Kuwano H: Inhibition of autophagy augments 5-fluorouracil chemotherapy in human colon cancer in vitro and in vivo model. Eur J Cancer 46: 1900-1909, 2010

27. Apel A, Zentgraf H, Buchler MW and Herr I: Autophagy-A double-edged sword in oncology. Int J Cancer 125: 991-995, 2009.

28. Eisenberg-Lerner A and Kimchi A: The paradox of autophagy and its implication in cancer etiology and therapy. Apoptosis 14: 376-391, 2009.

29. Dalby KN, Tekedereli I, Lopez-Berestein G and Ozpolat B: Targeting the prodeath and prosurvival functions of autophagy as novel therapeutic strategies in cancer. Autophagy 6: 322-329, 2010.

30. Ravikumar B, Sarkar S, Davies JE, Futter M, Garcia-Arencibia M, Green-Thompson ZW, Jimenez-Sanchez M, Korolchuk VI, Lichtenberg M, Luo S, et al: Regulation of mammalian autophagy in physiology and pathophysiology. Physiol Rev 90: 1383-1435, 2010.

31. Napetschnig $\mathrm{J}$ and $\mathrm{Wu} \mathrm{H}$ : Molecular basis of $\mathrm{NF}-\kappa \mathrm{B}$ signaling. Annu Rev Biophys 42: 443-468, 2013.

32. Perkins ND: The diverse and complex roles of NF- $\mathrm{kB}$ subunits in cancer. Nat Rev Cancer 12: 121-132, 2012.

33. Dai Y, Chen S, Wang L, Pei XY, Kramer LB, Dent P and Grant S: Bortezomib interacts synergistically with belinostat in human acute myeloid leukaemia and acute lymphoblastic leukaemia cells in association with perturbations in NF- $\kappa \mathrm{B}$ and $\mathrm{Bim}$. Br J Haematol 153: 222-235, 2011

34. Fang J, Rhyasen G, Bolanos L, Rasch C, Varney M, Wunderlich M, Goyama S, Jansen G, Cloos J, Rigolino C, et al: Cytotoxic effects of bortezomib in myelodysplastic syndrome/acute myeloid leukemia depend on autophagy-mediated lysosomal degradation of TRAF6 and repression of PSMA1. Blood 120: 858-867, 2012.

35. Riccioni R, Senese M, Diverio D, Riti V, Buffolino S, Mariani G, Boe A, Cedrone M, Lo-Coco F, Foà R, et al: M4 and M5 acute myeloid leukaemias display a high sensitivity to Bortezomib-mediated apoptosis. Br J Haematol 139: 194-205, 2007.

36. Ying M, Zhou X, Zhong L, Lin N, Jing H, Luo P, Yang X, Song H, Yang B and He Q: Bortezomib sensitizes human acute myeloid leukemia cells to all-trans-retinoic acid-induced differentiation by modifying the RAR $\alpha /$ STAT1 axis. Mol Cancer Ther 12: 195-206, 2013.

This work is licensed under a Creative Commons Attribution-NonCommercial-NoDerivatives 4.0 International (CC BY-NC-ND 4.0) License. 